Article

\title{
Computational Model of a Biomass Driven Absorption Refrigeration System
}

\author{
Munyeowaji Mbikan ${ }^{\dagger}$ and Tarik Al-Shemmeri *,† \\ Department of Mechanical Engineering, Staffordshire University, College Road, Stoke-On-Trent ST4 2DE, UK; \\ munyeowaji.mbikan@staffs.ac.uk \\ * Correspondence: T.T.Al-Shemmeri@staffs.ac.uk; Tel.: +44-178-535-3335 \\ $\dagger$ These authors contributed equally to this work.
}

Academic Editor: Vasily Novozhilov

Received: 12 December 2016; Accepted: 9 February 2017; Published: 16 February 2017

\begin{abstract}
The impact of vapour compression refrigeration is the main push for scientists to find an alternative sustainable technology. Vapour absorption is an ideal technology which makes use of waste heat or renewable heat, such as biomass, to drive absorption chillers from medium to large applications. In this paper, the aim was to investigate the feasibility of a biomass driven aqua-ammonia absorption system. An estimation of the solid biomass fuel quantity required to provide heat for the operation of a vapour absorption refrigeration cycle (VARC) is presented; the quantity of biomass required depends on the fuel density and the efficiency of the combustion and heat transfer systems. A single-stage aqua-ammonia refrigeration system analysis routine was developed to evaluate the system performance and ascertain the rate of energy transfer required to operate the system, and hence, the biomass quantity needed. In conclusion, this study demonstrated the results of the performance of a computational model of an aqua-ammonia system under a range of parameters. The model showed good agreement with published experimental data.
\end{abstract}

Keywords: absorption refrigeration; modelling; aqua-ammonia; biomass; renewable energies

\section{Introduction}

Refrigeration and cooling demand, either for indoor climate control or preservation and chilling purposes, cuts across every region of the globe. Conventional refrigeration and air-conditioning systems are high energy intensive systems [1,2]. In cases where a vapour compression refrigeration cycle (VCRC) applies, and a conventional energy source is used, the resulting climatic impact is two-fold-the effect of carbon dioxide emission from fossil fuel, and the ozone depletion effect from Hydrochlorofluorocarbons (HCFCs) and Hydrofluorocarbons (HFCs) refrigerants used in these systems. Research and development of technologies, aimed at reducing both the energy consumption and environmental impact of these systems, is on-going [3,4]. Ground source heating and cooling is one such emerging technology [5]. This involves exploring the ground's huge capacity to receive and supply heat for space heating and cooling. Others are solar powered refrigeration systems (mechanical compression or thermal sorption) [6,7], ground coupled solar panel cooling [8], and passive heating and cooling [1]. Passive heating and cooling involves strategic control of thermal conditions in buildings to improve indoor atmospheric conditions with near-zero energy consumption. The technology promises a huge energy benefit. However, its impact falls outside heavy refrigeration demands, and its application to existing buildings will be of high capital intensity, where possible. The vapour absorption refrigeration cycle (VARC) is a thermally driven system with very low electrical energy demand compared with the VCRC. VARC uses ozone depletion-free and environmentally friendly refrigerants. The thermal requirement of the VARC system can be met by inexpensive sources such as waste heat from industrial processes, and exhaust heat from engines, solar and biomass. 
As part of a trigeneration system, VARC is driven by hot water (Figure 1) generated in the boiler and split in three ways by three separate valves leading to the three applications. Operation of the absorption refrigeration systems with solar heat was studied by [7,9-14], and operation with waste heat recovery was studied by [15-18]. However, literature on biomass driven absorption cooling is scarce. In this paper, a computer model for the evaluation of a single-stage aqua-ammonia vapour absorption refrigeration system is developed. An important and new novelty aspect of this model is that the performance of the refrigeration cycle is coupled with the biomass fuel necessary to achieve it, and also, the determination of the actual value of the refrigerant vapour at the generator exit (state point 7, Figure 2) using the vapour split Rachford-Rice equation [19] which previous researchers have assumed to be $100 \%$; whereas, in this paper, it is actually determined using a combination of Equations (17)-(19).

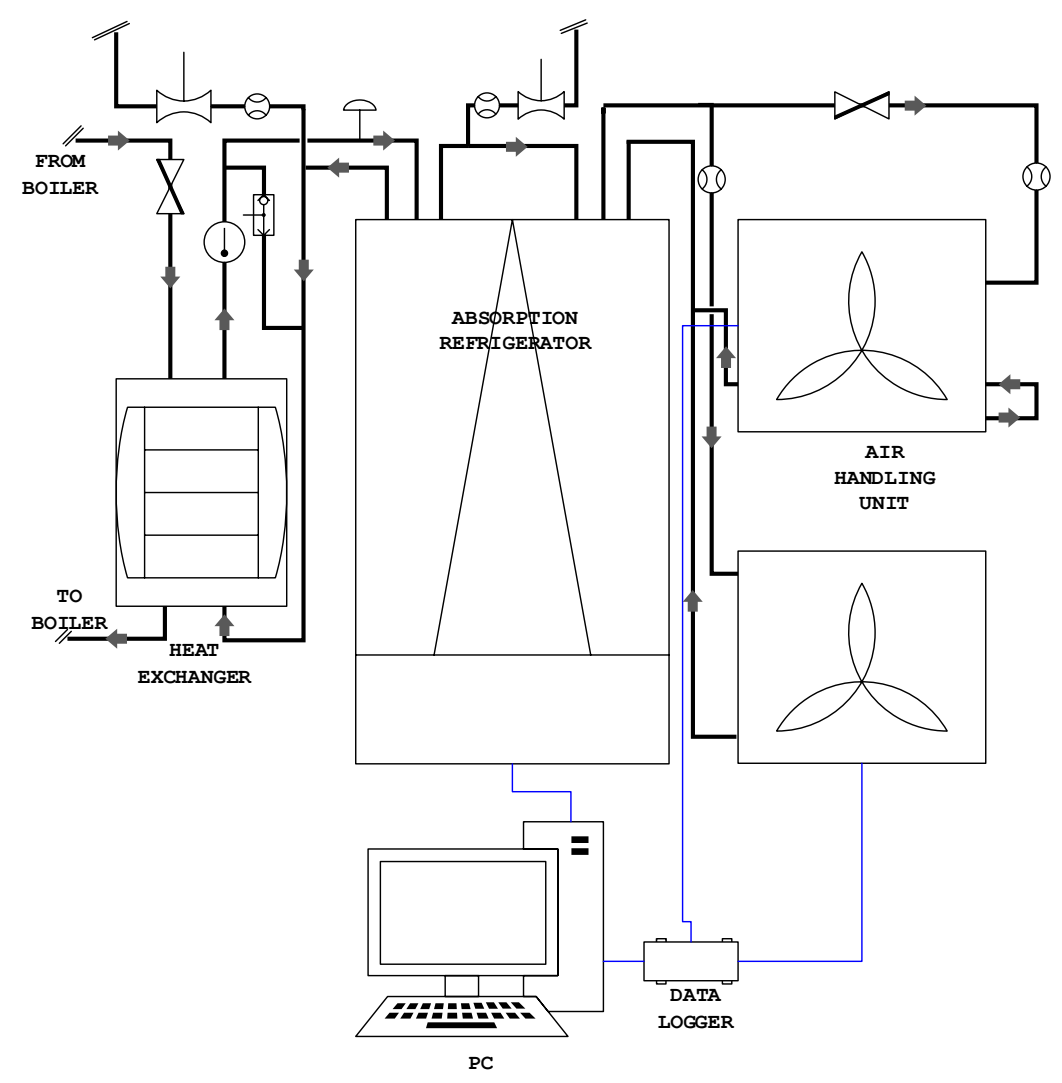

Figure 1. Absorption refrigeration test rig.

\section{Biomass Source to Drive Absorption Refrigeration}

Biomass refers to fuels produced directly or indirectly from organic materials. This includes plants, agricultural, domestic and industrial wastes. Biomass is carbon neutral and has been in use for energy production since the beginning of time; for many parts of the world, it is still the main source of heat. The growing production of biomass in recent times falls on the back of fossil fuel market volatility, environmental considerations, security concerns and energy supply diversification. Modern technologies have improved the efficiency of biomass fuels and enhance its cleanness far more than the traditional uses which are mainly open fires. As the fourth largest energy source, it is widely recognised as a potential sustainable global source of energy. The main annual global production of biomass is estimated to be equivalent to the $4500 \mathrm{EJ}$ of the annual global energy capture contributing about $10 \%$ of the global primary energy demand mainly in the form of traditional non-commercial biomass [20]; but now, biomass is known to be applied on a large scale with biomass boilers of over 500 MWth [21]; the potential to produce 50\% of Europe's total energy requirement from purposefully 
grown biomass such as dedicated energy crops and short rotation coppice (SRC) is proposed [22]. Most renewable energy sources depend on back-up power or a battery bank to forestall intermittent supply [23]. Biomass is one renewable source that can be used in many applications with hardly any need for back-up. This versatility is further enhanced by the emerging conversion technologies and the improvement of the existing ones, making it a flexible energy source [24]. However, the economic and environmental gains of biomass fuels are influenced by the proximity of the field-storage, and mode of transportation to the point of utilsation [25]. Biomass used for fuels is categorized into two main groups [26].

Woody Biomass:

- Forest residues;

- Wood waste;

- Crop residues;

- Wood crops (SRC, Willow, and Miscanthus).

Non-Woody Biomass:

- Animal wastes;

- Industrial and municipal wastes;

- High energy crops;

- Algae-a huge aquatic biomass source, with water covering about $75 \%$ of the earth.

Woody biomass is considered in this paper. The demand for biomass will vary for different end users but will generally depend on:

- Boiler capacity;

- Boiler efficiency;

- Operating hours;

- Type and availability of biomass.

\section{Modelling of the Aqua-Ammonia Refrigeration System}

Figure 2 is a schematic of the VARC. The refrigerant vapour leaving the evaporator at state 10 (low temperature and pressure side) is absorbed by a weak solution of ammonia coming from a pressure reduction valve at state point 6 . After absorbing ammonia vapour, it becomes a strong solution with respect to the concentration of ammonia in solution, and leaves the absorber at state 1 as a saturated liquid - the enthalpy of condensation being rejected and hence, the heat rejection $Q_{a}$ in the absorber. A liquid pump increases the pressure of the strong solution from the evaporator pressure $\left(p_{e}\right)$ to the condenser pressure $\left(p_{c}\right)$ through the solution heat exchanger where it is preheated by the warm weak solution and enters the generator at state 3 . The strong solution is heated in the generator to liberate the refrigerant. The weak solution leaves the generator at state 4 through the solution heat exchanger and leaves the solution expansion valve (pressure reduction valve) at state 6 back to the absorber. The refrigerant enters the condenser at state 7 at high pressure $p_{c}$ and the heat $Q_{c}$ is rejected to the surroundings by condensation at higher temperature. The liquid refrigerant leaves the condenser at state 8 and undergoes isentropic expansion, and enters the evaporator at state 9 where heat $Q_{e}$ is added from the space being cooled at low pressure, causing the refrigerant to boil, and the vapour leaves to the absorber at state 10, where it is absorbed by the weak solution.

Based on Figure $2, \dot{m}_{1}, \dot{m}_{6}$ and $\dot{m}_{10}(\mathrm{~kg} / \mathrm{s})$ are respectively, the flow rates of the strong solution, weak solution and the refrigerant, and $x_{1}, x_{6}$ and $x_{10}$ are ammonia mole fraction in the weak solution, strong solution and the refrigerant. $h_{i}(\mathrm{~kJ} / \mathrm{kg})$ is the state point enthalpy $i=1,2, \ldots, n$ is the state point. $Q_{i}(\mathrm{~kW})$ is the energy rate of change, where $i=A, C, E, G$ for the absorber, condenser, evaporator and generator, respectively. $T_{j k}$ is the flow temperature where $j$ is the component initial and $k$ indicates 
flow direction-i for inlet and o for outlet. $C O P_{\text {ref }}$-the performance coefficient of the refrigeration cycle-is the ratio of the heat supplied in the generator to the rate of heat transfer to the system from the surroundings (refrigeration capacity).
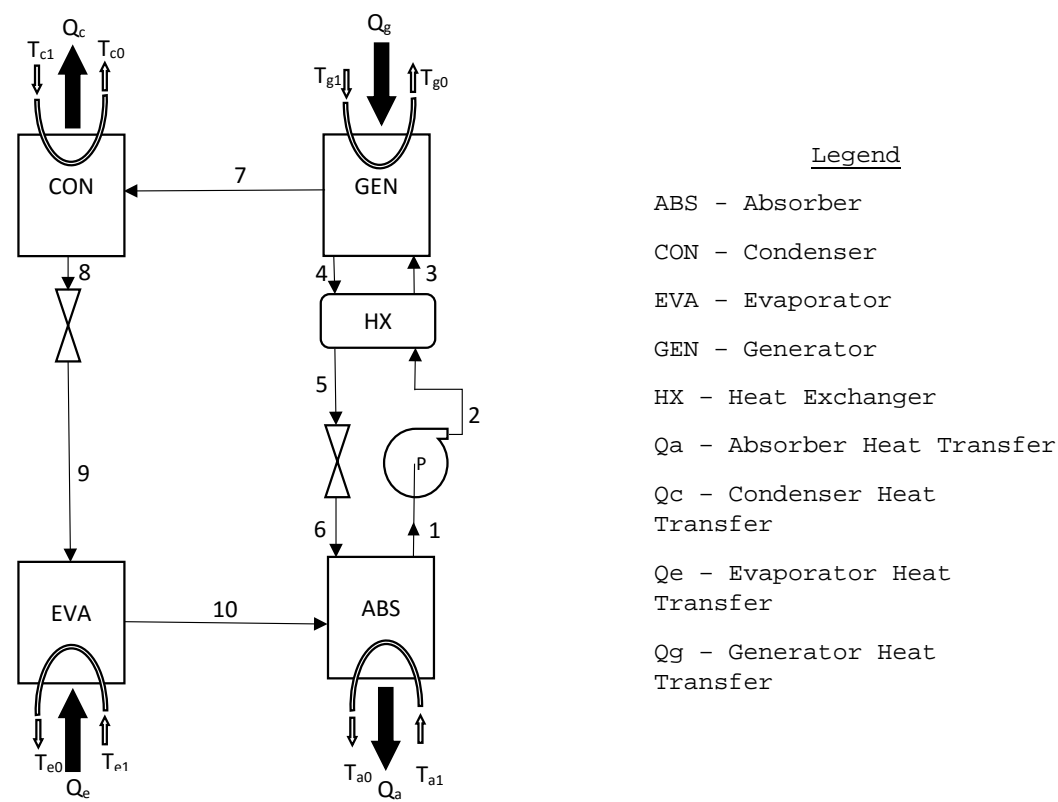

Figure 2. Schematic of the single-stage aqua-ammonia vapour absorption refrigeration system.

Mass conservation-overall:

$$
\dot{m}_{1}=\dot{m}_{6}+\dot{m}_{10}
$$

Mass conservation-ammonia:

$$
\dot{m}_{1} x_{1}=\dot{m}_{6} x_{6}+\dot{m}_{10} x_{10}
$$

Energy conservation:

$$
\dot{m}_{1} h_{1}=\dot{m}_{6} h_{6}+\dot{m}_{10} h_{10}
$$

Combining Equations (2) and (3):

$$
x_{1}=x_{6}+\left(\dot{m}_{10} / \dot{m}_{1}\right)\left(x_{10}-x_{6}\right)
$$

Circulation ratio $(f)$ :

$$
\begin{gathered}
f=\dot{m}_{1} / \dot{m}_{10} \\
x_{1}=x_{6}+(1 / f)\left(x_{10}-x_{6}\right)
\end{gathered}
$$

Similarly,

$$
h_{1}=h_{6}+(1 / f)\left(h_{10}-h_{6}\right)
$$

Energy balance-absorber:

$$
Q_{A}=\dot{m}_{10} h_{10}+\dot{m}_{6} h_{6}-\dot{m}_{1} h_{1}
$$

From Equations (4) and (5),

$$
Q_{A}=\dot{m}_{10}\left[h_{10}+(f-1) h_{6}\right]-\dot{m}_{1} h_{1}
$$


Energy balance-heat exchanger:

$$
Q_{h x}=\dot{m}_{6}\left(h_{4}-h_{6}\right)=\dot{m}_{1}\left(h_{3}-h_{2}\right)-w_{p}
$$

where $\dot{m}_{r}=\dot{m}_{10}=\dot{m}_{7}$-refrigerant mass flow, $x_{1}=x_{2}=x_{3}=X_{s s}$-strong solution (with respect to the ammonia concentration in solution) and $x_{4}=x_{5}=x_{6}=X_{w s}$-the weak solution.

Assume pump work $w_{p} \approx 0$ (negligible), the enthalpy at the generator inlet:

$$
h_{3}=h_{2}+(1 / f)\left(h_{4}-h_{5}\right)
$$

Energy balance-generator:

$$
\begin{gathered}
Q_{G}+\dot{m}_{1} h_{3}=\dot{m}_{10} h_{7}+\dot{m}_{6} h_{4} \\
Q_{G}=\dot{m}_{10}\left[h_{7}+(f-1) h_{4}\right]-\dot{m}_{1} h_{1}
\end{gathered}
$$

Energy balance—condenser:

$$
Q_{C}=\dot{m}_{10}\left(h_{7}-h_{8}\right)
$$

Energy balance-evaporator:

$$
Q_{E}=\dot{m}_{10}\left(h_{10}-h_{8}\right)
$$

Coefficient of performance:

$$
\operatorname{COP}_{r e f}=\frac{Q_{E}}{Q_{G}+w_{p}}=\frac{Q_{E}}{Q_{G}}
$$

\subsection{Governing Equations}

In order to fix the thermodynamic state for a compressible binary solution, the composition is required in addition to the two independent properties-temperature and pressure. The bubble point $\left(T_{b}\right)$ and dew point $\left(T_{d}\right)$ temperatures are calculated from the correlations developed by Patek and Klomfar [27]-Equation (13).

$$
\begin{gathered}
T_{b}(p, x)=T_{0} \sum_{i} a_{i}(1-x)^{m_{i}}\left[\ln \frac{p_{0}}{p}\right]^{n_{i}} \\
T_{d}(p, y)=T_{0} \sum_{i} a_{i}(1-y)^{\frac{m_{i}}{4}}\left[\ln \frac{p_{0}}{p}\right]^{n_{i}} \\
x=f(T, p) \\
y=f(T, p)
\end{gathered}
$$

where $T$ is temperature (K), $T_{0}, T_{b}$ and $T_{d}$ are the reference, bubble and dew points temperatures, respectively. The coefficients are shown in Tables 1 and 2. $x$ and $y$ are the ammonia mole fraction in the liquid and vapour phases, respectively.

$p_{0}=2 \mathrm{MPa}$ and $T_{0}=100 \mathrm{~K}$. The reduced thermodynamic properties are as follows:

$$
T_{0}=100 \mathrm{~K} ; p_{b}=10 \mathrm{bar} ; T_{r}=\frac{T}{T_{0}} ; p_{r}=\frac{p}{p_{b}} ; R=8.314 \mathrm{~J} / \mathrm{kmol}
$$

The composition of the solution phase is estimated from Equation (15), developed from Equation (13). To estimate the composition in the vapour phase, the vapour split, $V / F$, from Equation (18) is calculated from the Rachford-Rice [19] flash Equation (17) numerically using Matlab (fzero) function. The vapour composition is obtained from Equation (19). 


$$
\begin{gathered}
\sum_{i=1}^{S}\left(y_{i}-x_{i}\right)=\sum_{i=1}^{S} \frac{\left(K_{i}-1\right) z_{i}}{\left(\left(K_{i}-1\right) V+1\right)}=0,0 \leqslant \frac{V}{F} \leqslant 1 \\
x_{i}=\frac{z_{i}}{1+\frac{V}{F\left(K_{i}-1\right)}} \\
y_{i}=K_{i} x_{i}
\end{gathered}
$$

$K$-value defines the ratio of each component:

$$
K_{i}=\frac{y_{i}}{x_{i}}
$$

$F$ in the above Equations represents the feed with composition $z_{i} . V$ (with composition $y_{i}$ ) is the vapour product and $L$ (with composition $x_{i}$ ) is the liquid product.

Table 1. Coefficients for Equation (13).

\begin{tabular}{cccc}
\hline $\boldsymbol{i}$ & $\boldsymbol{m}_{\boldsymbol{i}}$ & $\boldsymbol{n}_{\boldsymbol{i}}$ & $\boldsymbol{a}_{\boldsymbol{i}}$ \\
\hline 1 & 0 & 0 & $+0.322302 \times 10^{1}$ \\
2 & 0 & 1 & -0.384206 \\
3 & 0 & 2 & $+0.460965 \times 10^{-1}$ \\
4 & 0 & 3 & $-0.378945 \times 10^{-2}$ \\
5 & 0 & 4 & $+0.135610 \times 10^{-3}$ \\
6 & 1 & 0 & +0.487755 \\
7 & 1 & 2 & -0.120108 \\
8 & 1 & 2 & $+0.106154 \times 10^{-1}$ \\
9 & 2 & 3 & $-0.533589 \times 10^{-3}$ \\
10 & 4 & 0 & $+0.785041 \times 10^{1}$ \\
11 & 5 & 0 & $-0.115941 \times 10^{1}$ \\
12 & 5 & 1 & $-0.523150 \times 10^{2}$ \\
13 & 6 & 0 & $+0.489596 \times 10^{-1}$ \\
14 & 13 & 1 & $0.421059 \times 10^{-1}$ \\
\hline
\end{tabular}

Table 2. Coefficients for Equation (14).

\begin{tabular}{cccc}
\hline $\boldsymbol{i}$ & $\boldsymbol{m}_{\boldsymbol{i}}$ & $\boldsymbol{n}_{\boldsymbol{i}}$ & $\boldsymbol{a}_{\boldsymbol{i}}$ \\
\hline 1 & 0 & 0 & $+0.324004 \times 10^{1}$ \\
2 & 0 & 1 & -0.395920 \\
3 & 0 & 2 & $-0.434624 \times 10^{-1}$ \\
4 & 0 & 3 & $-0.218943 \times 10^{-2}$ \\
5 & 1 & 0 & $-0.143526 \times 10^{1}$ \\
6 & 1 & 1 & $+0.105256 \times 10^{1}$ \\
7 & 1 & 2 & $-0.719281 \times 10^{-1}$ \\
8 & 2 & 0 & $+0.122362 \times 10^{2}$ \\
9 & 2 & 1 & $-0.224368 \times 10^{1}$ \\
10 & 3 & 0 & $-0.210780 \times 10^{2}$ \\
11 & 3 & 1 & $0.110834 \times 10^{1}$ \\
12 & 4 & 0 & $+0.145399 \times 10^{2}$ \\
13 & 4 & 2 & +0.644312 \\
14 & 5 & 2 & $-0.221264 \times 10^{1}$ \\
15 & 5 & 2 & -0.756266 \\
16 & 6 & 0 & $-0.135529 \times 10^{1}$ \\
17 & 7 & 2 & +0.183541 \\
\hline
\end{tabular}

The Equations for the enthalpy and the Gibbs free energy equation [28-30] are as follows:

$$
h=-R T_{b} T_{r}^{2}\left[\frac{\partial}{\partial T_{r}}\left(\frac{G_{r}}{T_{r}}\right)\right]
$$




$$
G=h_{0}-T S_{0}+\int_{T_{0}}^{T} C_{p} d T+\int_{p_{0}}^{p} v d p-T \int_{T_{0}}^{T}\left(\frac{C_{p}}{T}\right) d T
$$

The correlation for the heat capacity at constant pressure $\mathrm{Cp}$ and volume $v$ are given below:

$$
\begin{gathered}
C_{p l}=b_{1}+b_{2} T+b_{3} T^{2} \\
C_{p g}=d_{1}+d_{2} T+d_{3} T^{2}-T \int_{p_{0}}^{p}\left(\frac{\delta^{2} V}{\delta T^{2}}\right) d P \\
v_{l}=a_{1}+a_{2} p+a_{3} T^{2}+a_{4} T^{2} \\
v_{g}=\frac{R T}{p}+c_{1}+\frac{c_{2}}{T^{3}}+\frac{c_{3}}{T^{11}}+\frac{c_{4} p^{2}}{T^{11}}
\end{gathered}
$$

Equations (21)-(22) were solved with Mathcad using the correlations (23)-(26), to obtain (27) and (28). Equations (29) and (30) are the liquid ( $\left.h_{\text {liquid }}\right)$ and vapour $\left(h_{\text {vapour }}\right)$ phase enthalpy. The coefficients [28] are shown in Tables 3 and 4.

Table 3. Coefficients for Equations (27) and (28).

\begin{tabular}{ccc}
\hline Coefficients & Ammonia & Water \\
\hline$a_{1}$ & $3.971423 \times 10^{-2}$ & $2.748796 \times 10^{-2}$ \\
$a_{2}$ & $-1.790557 \times 10^{-5}$ & $-1.016665 \times 10^{-5}$ \\
$a_{3}$ & $-1.308905 \times 10^{-2}$ & $-4.452025 \times 10^{-3}$ \\
$a_{4}$ & $3.752836 \times 10^{-3}$ & $8.389264 \times 10^{-4}$ \\
$b_{1}$ & $1.634519 \times 10^{1}$ & $1.214557 \times 10^{1}$ \\
$b_{2}$ & -6.508119 & -1.898065 \\
$b_{3}$ & 1.448937 & $2.911966 \times 10^{-2}$ \\
$c_{1}$ & $-1.049377 \times 10^{-2}$ & $2.136131 \times 10^{-2}$ \\
$c_{2}$ & -8.288224 & $-3.169291 \times 10^{1}$ \\
$c_{3}$ & $-6.647257 \times 10^{2}$ & $-4.631611 \times 10^{4}$ \\
$c_{4}$ & $-3.045352 \times 10^{3}$ & 0.0 \\
$d_{1}$ & 3.673647 & 4.019170 \\
$d_{2}$ & $9.989629 \times 10^{-2}$ & $-5.175550 \times 10^{-2}$ \\
$d_{3}$ & $3.617622 \times 10^{-2}$ & $1.951939 \times 10^{-2}$ \\
$h_{0}^{l}$ & 4.87853 & 21.821141 \\
$h_{0}^{v}$ & 26.468879 & 60.965058 \\
$T_{r o}$ & 3.2252 & 3.0705 \\
$p_{r o}$ & 2.0000 & 3.0000 \\
\hline
\end{tabular}

Table 4. Coefficients for Equation (30).

\begin{tabular}{cccc}
\hline Coefficients & \multicolumn{3}{c}{ Coefficients } \\
\hline$e_{1}$ & -41.733398 & $e_{9}$ & 0.387983 \\
$e_{2}$ & 0.02414 & $e_{10}$ & 0.004772 \\
$e_{3}$ & 6.702285 & $e_{11}$ & -4.648107 \\
$e_{4}$ & -0.11475 & $e_{12}$ & 0.836376 \\
$e_{5}$ & 63.608968 & $e_{13}$ & -3.553627 \\
$e_{6}$ & -62.490768 & $e_{14}$ & 0.000904 \\
$e_{7}$ & 1.761064 & $e_{15}$ & 21.361723 \\
$e_{8}$ & 0.008626 & $e_{16}$ & -20.736547 \\
\hline
\end{tabular}

$$
h_{\text {liquid }}=-R T_{b}\left(-h_{0}^{l}+b_{1}\left(T_{r 0}-T_{r}\right)+\frac{b_{2}}{2}\left(T_{r 0}^{2}-T_{r 0}^{3}\right)+\left(a_{4} T_{r}^{2}-a_{1}\right)\left(p_{r}-p_{r 0}\right)-\frac{a_{2}}{2}\left(p_{r}^{2}-p_{r 0}^{2}\right)\right)
$$




$$
\begin{aligned}
h_{\text {vapour }}= & -R T_{b}\left[-h_{0}^{v}+d_{1} T_{r 0}+\frac{d_{2}}{2}\left(T_{r}^{2}-T_{r 0}^{2}\right)+\frac{d_{3}}{3}\left(2 T_{r}^{3}-T_{r 0}^{3}\right)-d_{1} T_{r}-d_{2} T_{r 0}^{2}-\frac{d_{3}}{2}\left(T_{r}^{2}-T_{r 0}^{2}\right)\right. \\
& \left.-c_{1}\left(p_{r}-p_{r 0}\right)+c_{2}\left(\frac{-4 p_{r}}{T_{r}^{3}}+\frac{4 p_{r 0}}{T_{r 0}^{3}}\right)+c_{3}\left(\frac{-12 p_{r}}{T_{r}^{11}}+\frac{12 p_{r 0}}{T_{r 0}^{11}}\right)+\frac{c_{4}}{3}\left(\frac{-12 p_{r}}{T_{r}^{3}}+\frac{12 p_{r 0}}{T_{r 0}^{3}}\right)\right]
\end{aligned}
$$

Equations (29) and (31):

$$
h^{l}=(1-x) h_{\text {liquid, } \mathrm{H}_{2} \mathrm{O}}+x h_{\text {liquid, } \mathrm{NH}_{3}}+h^{E}
$$

$h^{E}$ is the energy of mixing as shown in Equation (30).

$$
\begin{aligned}
h^{E}= & e_{1}+e_{2} p+\left(e_{3}+e_{4} p\right) T+\frac{e_{5}}{T}+\frac{e_{6}}{T^{2}}+(2 x-1) \\
& \left(e_{7}+e_{8} p+\left(e_{9}+e_{10} p\right) T+\frac{e_{11}}{T}+3 \frac{e_{12}}{T^{2}}+(2 x-1)^{2}\left(e_{13}+e_{14} p+\frac{e_{15}}{T}+\frac{e_{16}}{T^{2}}\right)\right)
\end{aligned}
$$

Similarly, the vapour phase enthalpy is given as shown in (31) where $y^{\prime}$ is the ammonia vapour fraction.

$$
h^{v}=\left(1-y^{\prime}\right) h_{\text {vapour }, \mathrm{H}_{2} \mathrm{O}}+y^{\prime} h_{\text {vapour }, \mathrm{NH}_{3}}
$$

The computation procedure for the analysis was implemented in Matlab. The coefficient of performance $(C O P)$, and the rate of energy due to the absorber, condenser, and generator are computed. The refrigeration capacity $\left(Q_{E}\right)$ is calculated (if it is not given as an input parameter) from the refrigerant mass flow; and the refrigerant mass flow is calculated if the $Q_{E}$ is given instead.

\subsection{Boiler Heat Exchanger Description}

Unlike the VCRC which relies on the power of the compressor-a high electrical energy consuming device-the VARC combines the affinity of the binary solution, a comparatively low energy consuming solution pump and thermal energy for the regeneration of the refrigerant and transport of fluid around the refrigeration cycle. The regenerating unit of the VARC can be operated by low grade heat from a variety of thermal sources including solar collectors, waste process heat from an exhaust and hot water or steam generating processes. Biomass solid fuels can be used to provide the required energy via the production of hot water [17]. The quantity of biomass required to operate a VARC for a given load is estimated based on the calorific value of the species. The heat generated in the boiler, from combusting biomass fuel, is used to heat water flowing through its circuitry and provides energy that is transferred through a heat exchanger to the generator circuit. A counter flow heat exchanger configuration (Figure 3) is used to enhance heat transfer of the hot water from the boiler to the regenerating unit.

The amount of heat required to raise the temperature of a substance is given as:

$$
q=m C_{p} \frac{d T}{t}
$$

For a continuous flow rate of change,

$$
q=\dot{m} C_{p} \frac{d T}{t}
$$

For a set temperature of hot water coming from the boiler and assuming that for the heat exchanger:

- $\quad$ Steady operating conditions apply;

- The heat exchanger is well insulated so that the heat loss to the surroundings is negligible;

- The kinetic and potential energy changes of the fluid are very small and negligible;

- No fouling conditions apply; 
- The properties of the fluid remain the same throughout the process.

the rate of heat required for the generator, for a set inlet and exit temperature, is estimated, and hence, the biomass quantity required for the load and operating duration:

$$
\dot{Q}_{h x}=\dot{m} C_{p}\left(T_{h i}-T_{h o}\right)
$$

and

$$
\dot{Q}_{G}=\dot{m} C_{p}\left(T_{c o}-T_{c i}\right)
$$

For a heat exchanger effectiveness of $E$,

$$
\dot{Q}_{h x}=\dot{m} C_{p} E\left(T_{h i}-T_{h o}\right)
$$

the rate of heat for Equations (34)-(36) is assumed to be same.

For boiler efficiency of $\eta_{B}$ and full load heating hours' equivalent (FLHE), the energy required $E_{R}$ and the biomass fuel quantity required $B_{Q}$, is estimated thus:

$$
E_{R}=\frac{Q_{h x} * F L H E}{\eta_{B}}
$$

where $Q_{h x}$ is the rate of heat transfer from the heat exchanger.

$$
B_{Q}=Q_{h x} * F_{d} * E_{R}
$$

$F_{d}$ is the fuel density of the biomass species.

The quality of combustion in the boiler depends on several factors including design, air velocity, air temperature, etc. The influence of the design factor which can be evaluated by Computational Fluid Dynamics (CFD) analysis [31], is not directly considered but assumed to be built into the boiler efficiency and the effectiveness of the heat exchanger.

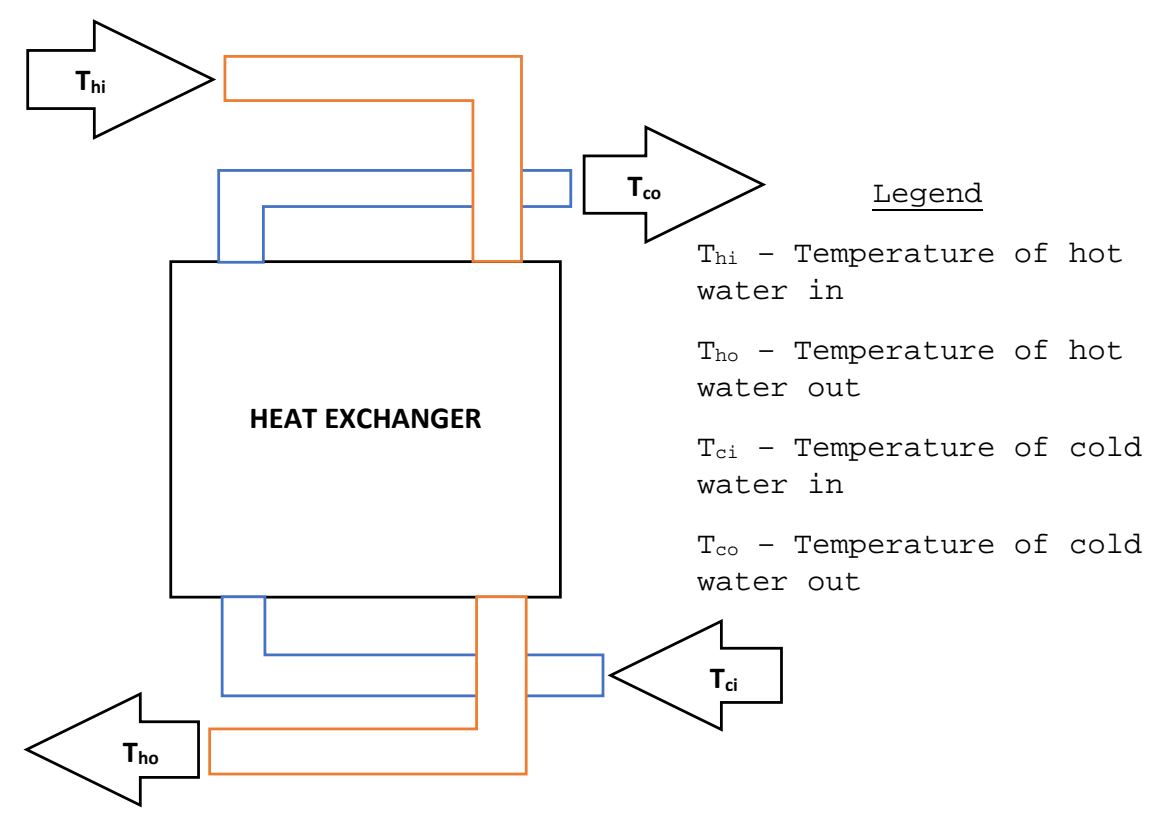

Figure 3. Heat exchanger. 


\section{Result and Discussion}

For a given operating condition, the quantity of biomass in tonnes $/ \mathrm{kW}$ required would vary in accordance with the energy density of the species. To perform an estimation calculation, the rate of heat transfer to the generator is first calculated. This is done by the computer simulation as described above.

\subsection{Biomass Quantity Required}

The rate of energy transfer due to the heat exchanger (Figure 3), the generator and the heat-loss is calculated as follows [13]:

$$
\begin{gathered}
Q_{G}=\dot{m}_{c} C_{p c}\left(T_{c i}-T_{c o}\right) \\
Q_{h x}=\dot{m}_{h} C_{p h}\left(T_{h o}-T_{h i}\right) \\
\dot{q}_{\text {loss }}=U A_{h x} *\left(T_{h x}-T_{a m b}\right)+U A_{G} *\left(T_{G}-T_{a m b}\right)
\end{gathered}
$$

where $T_{h x}=T_{h i}-T_{c i}$.

$$
\begin{gathered}
Q_{h x}=Q_{G}+\dot{q}_{\text {loss }} \\
B_{Q}=Q_{G}+\dot{q}_{\text {loss }} *\left(\frac{F L H E}{F_{d} * \eta_{B}}\right)
\end{gathered}
$$

Equation (41) is the total rate of energy loss for the system apart from the boiler, and Equation (42) relates the energy transfer rate due to the heat exchanger to that of the generator. The biomass quantity required is given by Equation (43), where $Q_{G}$ is the rate of energy transfer at the generator of the absorption refrigeration system. The equation shows that the quantity of biomass required for a given load over a time period would depend on the density of the biomass species and the boiler efficiency. Four biomass solid fuel types were compared. The energy densities are given in Table 5. It is observed that the higher the energy content of the fuel ( $\mathrm{kWh} /$ tonne), the less the quantity required. Figure 4. shows that the higher the temperature of the generator, the higher the quantity of fuel required, provided all other operating conditions are held constant. The mass of fuel required increased as the flow rate of hot water from the boiler is increased (Figure 5). Woodchips with the least dense energy content of the fuels under consideration, require nearly twice the mass of wood, with the highest energy content, for the same operation.

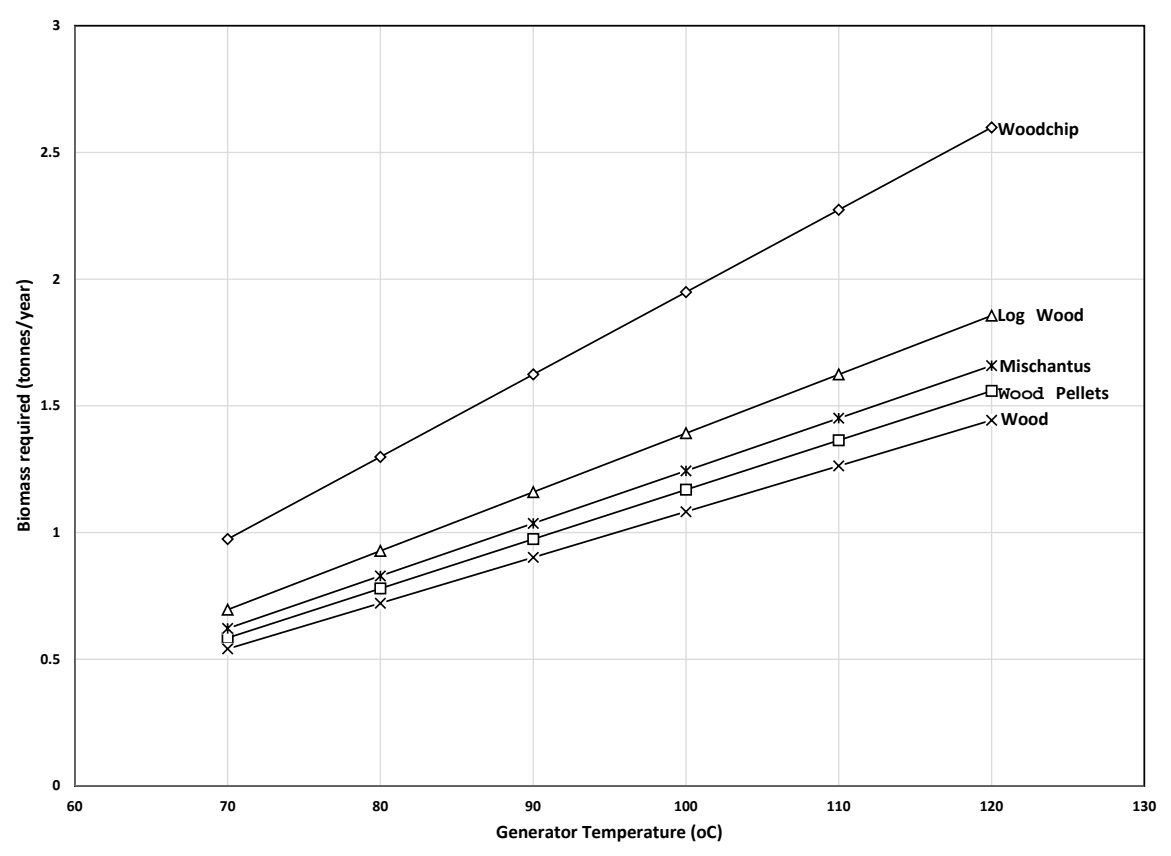

Figure 4. Comparison of fuel consumed with varied generator temperature. 
Table 5. Average densities of biomass solid fuels [32]. MC: moisture content.

\begin{tabular}{cc}
\hline Fuel Type & Average Energy Density (kJ/tonne) \\
\hline Wood chip (30\% MC) & 3000 \\
Wood pellets & 5000 \\
Log wood (stacked-air dried; 20\% MC) & 4200 \\
Wood & 5400 \\
Mischantus & 4700 \\
\hline
\end{tabular}

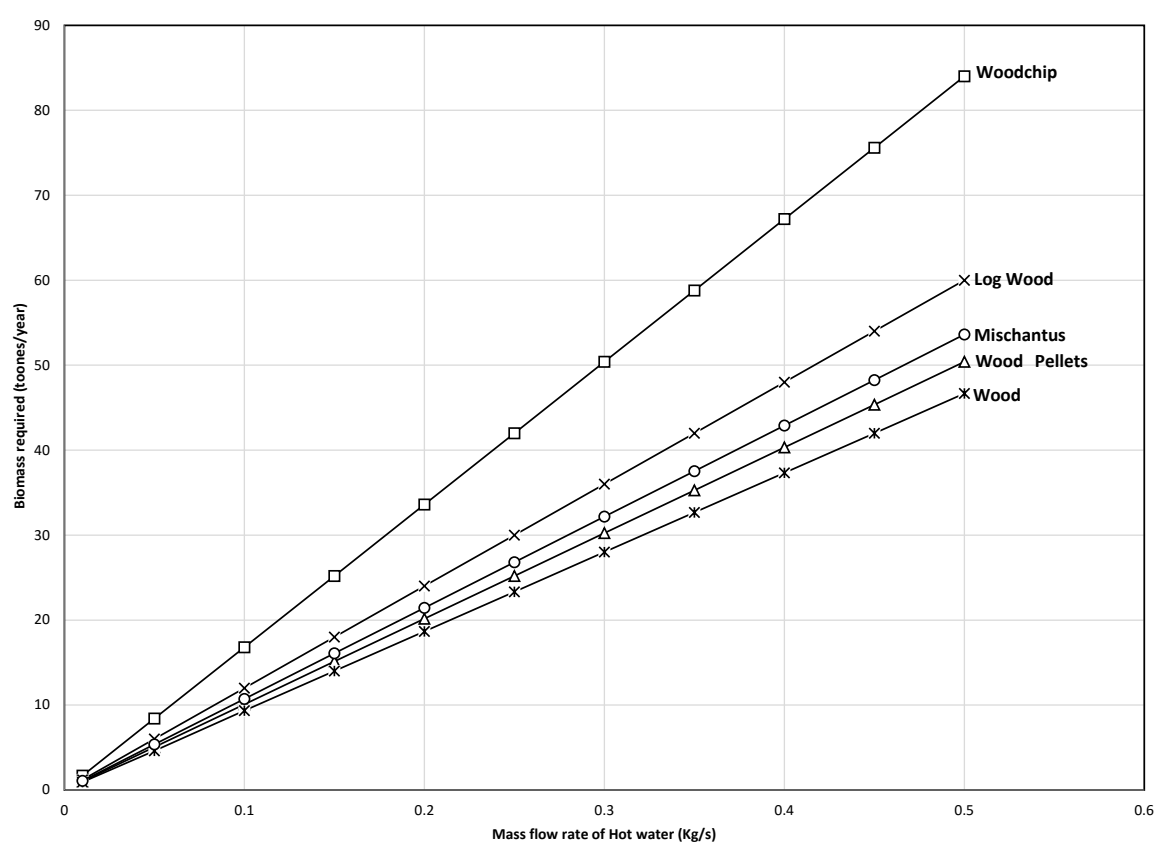

Figure 5. Effect of mass flow rate of hot water on fuel consumption.

\subsection{Absorption Refrigeration}

In calculating the $C O P$, it is assumed that no pressure drops except through the expansion valves and the flow pumps. Pumping is isentropic; at state points 1, 4, and 8, the liquid is saturated; the composition of the solution at state points 1, 2, and 3 (strong solution), and 4, 5, and 6 (weak solution) remain unchanged throughout the process. The condenser pressure (high pressure) is the same as that at state points 3, 4 and 7, while the evaporator pressure (low pressure) holds for points 1, 6 and 10 . The pump work is neglected, the refrigerant heat exchanger is not considered, and the generator is considered a single unit. simulated results from the absorption refrigeration cycle model developed were compared with published dated from the referenced authors [33-35]. The comparison was selected to reflect conditions of both light $\left(T_{E}=2.5^{\circ} \mathrm{C}, T_{A}=20^{\circ} \mathrm{C}, T_{C}=20{ }^{\circ} \mathrm{C}, T_{G}=60 \rightarrow 90{ }^{\circ} \mathrm{C}\right)$ and heavy cooling $\left(T_{G}=100{ }^{\circ} \mathrm{C}, T_{C}=40^{\circ} \mathrm{C}, T_{A}=30^{\circ} \mathrm{C}, T_{E}=-5^{\circ} \mathrm{C}, \dot{m}_{r}=1 \mathrm{~kg} / \mathrm{s}, E=0.80\right.$, $p_{e}=354.42 \mathrm{kPa}, p_{c}=1166.92 \mathrm{kPa}$ ) requirements. The results, show close similarity with a variation of \pm 0.02 . Table 6 shows the comparison of the variation of the solution composition and refrigerant circulation ratio with generator temperature. The variation of the energy rate of change in the various heat-exchanger units and COP with the generator temperature is presented in Tables 7 and 8 . The slight divergence in the result is to be expected partly due to the assumptions made. The temperature and pressure of the solution at the heat exchanger are computed by the model. Also, the composition of the refrigerant vapour at the exit of the generator is computed and not assumed; these parameters are normally estimated. In the calculation of the $C O P$, the solution pump work was considered in the references. However, it is neglected in this work (Figure 6). 
Table 6. Comparison of the flows of solution and refrigerant ratio at varied generator temperature $\left(T_{E}=2.5^{\circ} \mathrm{C}, T_{C}=20^{\circ} \mathrm{C}\right.$, and $\left.T_{A}=20^{\circ} \mathrm{C}\right)$.

\begin{tabular}{ccccc}
\hline Literature & Generator Temp $\left({ }^{\circ} \mathbf{C}\right)$ & Weak Sol (\%) & Strong Sol (\%) & Circulation Ratio $(f)$ \\
\hline Sun [34] & 60 & 47.1 & 62.4 & 3.41 \\
Present work & 60 & 47.1 & 62.5 & 3.40 \\
\hline Sun [34] & 70 & 41.4 & 62.6 & 2.70 \\
Present work & 70 & 41.4 & 62.6 & 2.76 \\
\hline Sun [34] & 80 & 36.2 & 62.5 & 2.4 \\
Present work & 80 & 36.4 & 62.5 & 2.4 \\
\hline Sun [34] & 90 & 31.4 & 62.5 & 2.2 \\
Present work & 90 & 31.5 & 62.5 & 2.2 \\
\hline
\end{tabular}

Table 7. Comparison of the energy flows and coefficient of performance $(C O P)$ at varied generator temperature $\left(T_{E}=2.5^{\circ} \mathrm{C}, T_{C}=20^{\circ} \mathrm{C}\right.$, and $\left.T_{A}=20^{\circ} \mathrm{C}\right)$.

\begin{tabular}{ccccccc}
\hline Literature & Generator Temp $\left({ }^{\circ} \mathbf{C}\right)$ & $Q_{G}(\mathbf{k W})$ & $Q_{C}(\mathbf{k W})$ & $Q_{A}(\mathbf{k W})$ & $Q_{E}(\mathbf{k W})$ & $C O P$ \\
\hline Sun [34] & 60 & 25.73 & 21.8 & 24.43 & 20.52 & 0.80 \\
Present work & 60 & 25.84 & 21.6 & 26.5 & 21.75 & 0.84 \\
\hline Sun [34] & 70 & 26.14 & 21.94 & 24.73 & 20.52 & 0.78 \\
Present work & 70 & 26.19 & 21.47 & 23.80 & 20.76 & 0.79 \\
\hline Sun [34] & 80 & 26.55 & 21.99 & 25.10 & 20.52 & 0.77 \\
Present work & 80 & 26.65 & 20.13 & 25.70 & 20.65 & 0.77 \\
\hline Sun [34] & 90 & 26.92 & 21.97 & 25.48 & 20.52 & 0.76 \\
Present work & 90 & 27.19 & 20.31 & 24.40 & 20.81 & 0.76 \\
\hline
\end{tabular}

Table 8. Comparison of the energy flows and $\mathrm{COP}\left(T_{E}=-5{ }^{\circ} \mathrm{C}, T_{C}=40{ }^{\circ} \mathrm{C}, T_{A}=30{ }^{\circ} \mathrm{C}\right.$ and $\left.T_{G}=100^{\circ} \mathrm{C}\right)[33,35]$.

\begin{tabular}{cccccc}
\hline Literature & $Q_{g}(\mathbf{k W})$ & $Q_{E}(\mathbf{k W})$ & $Q_{A}(\mathbf{k W})$ & $Q_{C}(\mathbf{k W})$ & $C O P$ \\
\hline Sun [35] & 30.131 & 18.597 & 30.327 & 18.461 & 0.617 \\
\hline Present work & 29.781 & 20.936 & 29.838 & 20.079 & 0.703
\end{tabular}

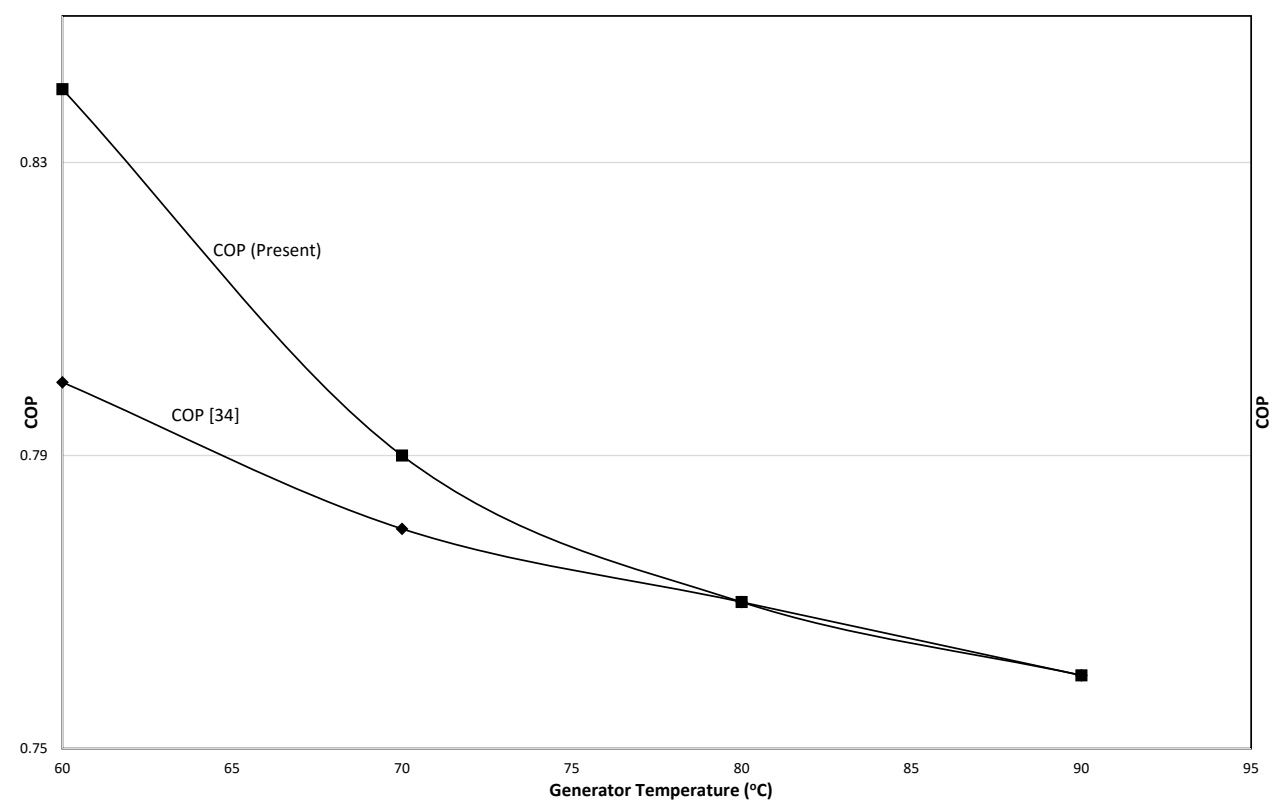

Figure 6. Comparison of the present work with published data in [34]. 


\section{Conclusions}

A routine for the analysis of a single stage aqua-ammonia refrigeration system has been developed. It estimates the concentration of the strong and the weak solutions as well as calculating the concentration of ammonia in the refrigerant vapour. The calculated COP, properties and rate of energy transfer in all components are reasonably approximated. Simulation results were produced for a practical range of heat inputs. Results were compared with published data and found good agreement. The use of biomass thermal energy which is renewable is proved to provide a $\mathrm{CO}_{2}$ free refrigeration option. However, the economic viability and carbon footprint will depend on availability, proximity to source, system size, full load operating hours and storage capacity required. Prediction of the biomass quantity required could be useful in the economic evaluation of the feasibility of operating an absorption refrigeration system with biomass, particularly for areas with access to biomass.

Acknowledgments: This paper presents a summary of some the results from the project "ARBOR" sponsored by the European Union, INTERREG IVB, NWE to promote the conversion of Biomass for Energy.

Author Contributions: Munyeowaji Mbikan carried out the numerical computation. Tarik Al-Shemmeri is the principal supervisor of the research.

Conflicts of Interest: The authors declare no conflict of interest in the publication of this paper.

\section{Nomenclature}

$A_{G} \quad$ Area of generator heat transfer surface $\left(\mathrm{m}^{2}\right)$

$A_{h x} \quad$ Area of heat transfer surface of heat exchanger $\left(\mathrm{m}^{2}\right)$

$B_{Q} \quad$ Biomass Quantity (Tonnes)

$C_{p} \quad$ Specific heat capacity $(\mathrm{kJ} / \mathrm{kgK})$

$E_{R} \quad$ Energy Required $(\mathrm{kW} / \mathrm{h})$

$f \quad$ Circulation ratio

$F_{d} \quad$ Fuel density $\left(\mathrm{kJ} / \mathrm{m}^{3}\right)$

FLHE Full load heating hours equivalent (h)

$h_{\text {liquid }} \quad$ Enthalpy of liquid component $(\mathrm{kJ} / \mathrm{kg})$

$h_{\text {vapour }}$ Enthalpy of vapour component $(\mathrm{kJ} / \mathrm{kg})$

$h^{l} \quad$ Liquid phase enthalpy $(\mathrm{kJ} / \mathrm{kg})$

$h^{v} \quad$ Vapour phase enthalpy $(\mathrm{kJ} / \mathrm{kg})$

MC Moisture content (\%)

$\dot{m}_{r} \quad$ Refrigerant mass flow $(\mathrm{kg} / \mathrm{s})$

$p_{c} \quad$ Condenser pressure (MPa)

$p_{e} \quad$ Evaporator pressure (MPa)

$Q_{A} \quad$ Absorber heat transfer $(\mathrm{kW})$

$Q_{C} \quad$ Condenser heat transfer $(\mathrm{kW})$

$Q_{E} \quad$ Evaporator heat transfer $(\mathrm{kW})$

$Q_{G} \quad$ Generator heat transfer $(\mathrm{kW})$

$Q_{h x} \quad$ Heat exchanger heat transfer $(\mathrm{kW})$

$\dot{q}_{\text {loss }} \quad$ Rate of heat loss $(\mathrm{kW})$

$T_{a m b} \quad$ Ambient temperature $\left({ }^{\circ} \mathrm{C}\right)$

$T_{c i} \quad$ Temperature of cold water at inlet $\left({ }^{\circ} \mathrm{C}\right)$

$T_{c o} \quad$ Temperature of cold water at outlet $\left({ }^{\circ} \mathrm{C}\right)$

$T_{h i} \quad$ Temperature of hot water at inlet $\left({ }^{\circ} \mathrm{C}\right)$

$T_{h o} \quad$ Temperature of hot water at outlet $\left({ }^{\circ} \mathrm{C}\right)$

$\mathrm{U} \quad$ Overall heat transfer coefficient

$\eta_{B} \quad$ Boiler Efficiency (\%)

\section{References}

1. Santamouris, M.; Argiriou, A. Renewable energies and energy conservation technologies for buildings in southern Europe. Int. J. Sol. Energy 1994, 15, 69-79.

2. Santamouris, M.; Papanikolaou, N.; Livada, I.; Koronakis, I.; Georgakis, C.; Argiriou, A.; Assimakopoulos, D. On the impact of urban climate on the energy consumption of buildings. Sol. Energy 2001, 70, 201-216. 
3. Ullah, K.; Saidur, R.; Ping, H.; Akikur, R.; Shuvo, N. A review of solar thermal refrigeration and cooling methods. Renew. Sustain. Energy Rev. 2013, 24, 499-513.

4. Florides, G.A.; Tassou, S.A.; Kalogirou, S.A.; Wrobel, L.C. Review of solar and low energy cooling technologies for buildings. Renew. Sustain. Energy Rev. 2002, 6, 557-572.

5. Banks, D. An Introduction to Thermogeology: Ground Source Heating and Cooling, 2nd Ed.; Wiley-Blackwell: Oxford, UK, 2012.

6. Kim, D.S.; Infante Ferreira, C.A. Solar refrigeration options-A state-of-the-art review. Int. J. Refrig. 2008, 31, 3-15.

7. Fan, Y.; Luo, L.; Souyri, B. Review of solar sorption refrigeration technologies: Development and applications. Renew. Sustain. Energy Rev. 2007, 11, 1758-1775.

8. Sahay, A.; Sethi, V.K.; Tiwari, A.C.; Pandey, M. A review of solar photovoltaic panel cooling systems with special reference to Ground coupled central panel cooling system (GC-CPCS). Renew. Sustain. Energy Rev. 2015, 42, 306-312.

9. Siddiqui, M.U.; Said, S.A.M. A review of solar powered absorption systems. Renew. Sustain. Energy Rev. 2015, 42, 93-115.

10. Desideri, U.; Proietti, S.; Sdringola, P. Solar-powered cooling systems: Technical and economic analysis on industrial refrigeration and air-conditioning applications. Appl. Energy 2009, 86, 1376-1386.

11. Said, S.A.M.; El-Shaarawi, M.A.I.; Siddiqui, M.U. Alternative designs for a 24-h operating solar-powered absorption refrigeration technology. Int. J. Refrig. 2012, 35, 1967-1977.

12. Sarbu, I.; Sebarchievici, C. General review of solar-powered closed sorption refrigeration systems. Energy Convers. Manag. 2015, 105, 403-422.

13. Bales, C.; Ayadi, O. Modelling of commercial absorption heat pump with integral storage. In Proceedings of the 11th International Conference on Energy Storage, Stockholm, Sweden, 14-17 June 2009.

14. Mathkor, R.Z.; Agnew, B.; Al-Weshahi, M.A.; Latrsh, F. Exergetic analysis of an integrated tri-generation organic rankine cycle. Energies 2015, 8, 8835-8856.

15. Kalinowski, P.; Hwang, Y.; Radermacher, R.; Al Hashimi, S.; Rodgers, P. Application of waste heat powered absorption refrigeration system to the LNG recovery process. Int. J. Refrig. 2009, 32, 687-694.

16. Manzela, A.A.; Hanriot, S.M.; Cabezas-Gómez, L.; Sodré, J.R. Using engine exhaust gas as energy source for an absorption refrigeration system. Appl. Energy 2010, 87, 1141-1148.

17. Lin, L.; Wang, Y.; Al-Shemmeri, T.; Zeng, S.; Huang, X.; Li, S.; Yang, J. Characteristics of a diffusion absorption refrigerator driven by waste heat from engineexhaust. Proc. Instit. Mech. Eng. Part E J. Process Mech. Eng. 2006, 220, 139-149.

18. Lin, L.; Wang, Y.; Al-Shemmeri, T.; Ruxton, T.; Turner, S.; Zeng, S.; Huang, J.; He, Y.; Huang, X. An experimental investigation of a household size trigeneration. Appl. Therm. Eng. 2007, 27, 576-585.

19. Rachford, H.H.; Rice, J.D. Procedure for use of electrical digital computers in calculating flash vaporization hydrocarbon equilibrium. Trans. AIME 1952, 4, 19-20.

20. Ladanai, S.; Vinterbäck, J. Global Potential of Sustainable Biomass for Energy; Department of Energy and Technology, Institutionen för Energi Och Teknik Swedish University of Agricultural Sciences: Uppsala, Sweden, 2009; p. 32.

21. Caillat, S.; Vakkilainen, E. Chapter 9-Large-scale biomass combustion plants: An overview. In Biomass Combustion Science, Technology and Engineering; Elsevier: Amsterdam, The Netherlands, 2013; pp. 189-224.

22. Bridgwater, A.V. The technical and economic feasibility of biomass gasification for power generation. Fuel 1995, 74, 631-653.

23. Treado, $\mathrm{S}$. The effect of electric load profiles on the performance of off-grid residential hybrid renewable energy systems. Energies 2015, 8, 11120-11138.

24. Long, H.; Li, X.; Wang, H.; Jia, J. Biomass resources and their bioenergy potential estimation: A review. Renew. Sustain. Energy Rev. 2013, 26, 344-352.

25. Sopegno, A.; Rodias, E.; Bochtis, D.; Busato, P.; Berruto, R.; Boero, V.; Sørensen, C. Model for energy analysis of Miscanthus production and transportation. Energies 2016, 9, 392.

26. Bekele, K.; Hager, H.; Mekonnen, K. Woody and non-woody biomass utilisation for fuel and implications on plant nutrients availability in the mukehantuta watershed in ethiopia. Afr. Crop Sci. J. 2013, 21, 625-636.

27. Pátek, J.; Klomfar, J. Simple functions for fast calculations of selected thermodynamic properties of the ammonia-water system. Int. J. Refrig. 1995, 18, 228-234. 
28. Ziegler, B.; Trepp, C. Equation of state for ammonia-water mixtures. Int. J. Refrig. 1984, 7, 101-106.

29. Kherris, S.; Makhlouf, M.; Zebbar, D.; Sebbane, O. Contribution study of the thermodynamics properties of the ammonia-water mixtures. Therm. Sci. 2013, 17, 891-902.

30. Ganesh, N.S.; Srinivas, T. Evaluation of thermodynamic properties of ammonia- water mixture up to 100 bar for power application systems. J. Mech. Eng. Res. 2011, 3, 25-39.

31. Collazo, J.; Porteiro, J.; Míguez, J.L.; Granada, E.; Gómez, M.A. Numerical simulation of a small-scale biomass boiler. Energy Convers. Manag. 2012, 64, 87-96.

32. Martin, R.; Mark, M. Biomass Heating: A Practical Guide for Potential Users; In-Depth Guide CTG012; Carbon Trust: London, UK, 2007.

33. Cai, W.; Sen, M.; Paolucci, S. Dynamic simulation of an ammonia-water absorption refrigeration system. Ind. Eng. Chem. Res. 2012, 51, 2070-2076.

34. Sun, D.W. Thermodynamic design data and optimum design maps for absorption refrigeration systems. Appl. Therm. Eng. 1997, 17, 211-221.

35. Sun, D.W. Comparison of the performances of $\mathrm{NH}_{3}-\mathrm{H}_{2} \mathrm{O}, \mathrm{NH}_{3}-\mathrm{LiNO}_{3}$ and $\mathrm{NH}_{3}-\mathrm{NaSCN}$ absorption refrigeration systems. Energy Convers. Manag. 1998, 39, 357-368.

(C) 2017 by the authors; licensee MDPI, Basel, Switzerland. This article is an open access article distributed under the terms and conditions of the Creative Commons Attribution (CC BY) license (http:/ / creativecommons.org/licenses/by/4.0/). 